\title{
GOVERNANCE TEAM LEADERSHIP AND BUSINESS USER PARTICIPATION - ORGANIZATIONAL PRACTICES FOR INNOVATIVE CUSTOMER ENGAGEMENT IN DATA COMPLIANCE PROJECT
}

\author{
Vojvodic, M., Hitz, C.
}

Milomir Vojvodic, Christian Hitz / University of Economics, Prague, Faculty of Business Administration, Czech Republic. Email: mvojvodic@gmail.com, christian.hitz@zhaw.ch

\begin{abstract}
The study examines the relationship between the governance program teams, business user participation, and innovation in data compliance projects. Many firms continue to struggle with their governance programs as its effective implementation requires organizational change and a higher rate of involvement of those with significant knowledge of the context of the system use. Leadership elements are observed in governance teams and the way how these elements impact both, participation and innovation in recent General Data Protection Regulation (GDPR) data compliance efforts.

To test the hypotheses, a quantitative method with Structural Equation Modelling and Partial Least Squares (PLS) in SmartPLS tool are used. The empirical data are collected from 98 data management professionals involved in projects associated with customers' data in larger organizations across European Union (EU).

Research findings show that Governance Team Leadership (GTL) influence positively Lineof-Business Stakeholders Participation (LOBSP) and LOBSP influence positively Data Compliance Innovation (DCl) in GDPR efforts. Moreover, it shows that LOBSP is the underlying mechanism (mediator) of the relationship GTL and $\mathrm{DCl}$.

Data governance transfers data and information management towards managerial functions and strategic management.

Data has become embedded within nearly every department and business unit, and its proper enterprise-wide governance requires much more rigorous alignment with business users and formation of one cross-functional unit - data stewardship team of proactive leaders. In opportunities and restrictions of data revolution underway, evidence of any sustainable organizational practices leading to innovations and competitive advantage is beneficial.
\end{abstract}

Keywords: data compliance, leadership, innovation, data governance JEL Classification: M15, M21 


\section{Introduction}

Firms are aiming to break down the silos of information and unlock trusted information to flow freely wherever it is required. Due to the rise in data availability and new data-driven insights, more and more data is being exchanged within and among companies. This has spawned a new data economy built upon using data to generate value. Increasing customer expectations and technological advancements transform companies into assembly lines of complete solutions with digital ecosystems of partners, this way raising performance, offering more user-centric products and services, fostering innovation - often leaving decades-old competitors behind.

EU Commission in the Official EU Journal (2016) introduced the European Union General Data Protection Regulation (GDPR) on the processing and use of personal data, which entered into force on 25 May 2018. While it is expected still to change and evolve, this legal data framework has the potential to yield benefits for common EU data market, unifying data regime, and increasing data flow (Duch-Brown, 2017).

GDPR regulation provides one more interaction channel with customers, and such new regulation response can be used this time alongside customer engagement strategy. Sawhney et al. (2005) suggest that this would gain a competitive advantage if the interaction is used in an innovative new way and as a flow of greater insights into customers' needs. Similarly, openness and proactivity with customers in terms of transparency on how their data is used - is an additional opportunity for engagement, loyalty, and trust. In the same way, Brodie et al. (2011) argue that customer data utilization and customer engagement bring customer satisfaction and represent a strategic imperative for generating sales growth and superior competitive advantage and profitability.

This relates to strategic management. Ritter et al. (2002) suggest that interactions can be seen as a network competence and element of competitive strength. Firms capable of using their resources most effectively will benefit from greater profits in the current competitive environment (M. Porter, 1998). Real resource utilization is based on creating unique solutions to existing business problems, utilizing innovation and creativity (Naletelich, 2015).

The research operationalizes this as Data Compliance Innovation (DCl), as aim for an innovative competitive strategy to respond to modern data compliance regulations such is GDPR.

Korhonen et al. (2013) suggest that obviously beside utilization of obvious opportunities, appropriate safeguards and measures need to be put in place to protect sensitive information and fulfil compliance requirements and strictly govern such data. As data has become embedded within nearly every department and business unit, then proper governance program would require organizational change, best organizational practice and business user participation (Payne \& Frow, 2005).

Komssi et al. (2015) outline that greater leverage and integration of the existing knowledge of the data about customers lies within the involvement and participation of stakeholders from line-of-business. The move the data management profession from low-level operations 
towards managerial functions is necessary, where information governance concept fits as it combines the best practices from strategic management, business process management, risk management, and IT governance (Niemi \& Laine, 2016).

The research operationalizes this as Line-of-Business Stakeholder Participation (LOBSP), the dimension of successful governance program that impacts data compliance collaboration and innovative ideas on the front end of customers.

Despite the growing importance of such holistic initiatives, many organizations continue to struggle with their governance programs seeing it as a large-scale undertaking, as its effective implementation can be transformational (Mittal \& Dhar, 2015). Vrhovec et al. (2015) describe that the challenges of larger information technology (IT) projects and programs are that IS changes are not coordinated with organizational changes. Resistance against organizational change is the dominant reasons for the inefficiency of operations while leading the rational implementation of organizational change.

Governance program assigned initiators and coordinators of data policies and rules within their unit of functions - data stewards are facing this resistance challenge as they do not have enough authority to ensure them power - than their way towards becoming leaders and influencers in inevitable. Some researchers have demonstrated that leadership, leaders, and influencers certainly play a major role in IT implementation success or failure (Aladwani, 2001; Lorenzi \& Riley, 2003) and that no single resource is more vital than proactivity and leadership for the planned transformation (Mhatre, 2014). Therefore, there is a need for specifications of program leader behaviours and suggestions to management by integrating information governance with change management and leadership theories.

The research operationalizes this as Governance Team Leadership (GTL), influential in the way how governance impacts line of business stakeholders participation and innovative competitive advantage related dimensions of GDPR.

This leads us to the following main research question: Do proactivity and leadership of data stewards in the governance team and increased participation from line-of-business stakeholders lead to innovation in data compliance projects?

There are also supportive research questions: What is the relationship between independent variables? Does leadership governance team lead to an increase in participation from line-of-business stakeholders? Is the participation from line-of-business stakeholders underlying mechanisms of governance team leadership - data compliance innovation relation?

\section{Practical contribution}

All hypothesis of this study is organizational practice driven. This research offers a line-ofbusiness participation' as a management tool to increase innovation in data compliance project. The research proves this in the GDPR regulation case. If it is necessary to increase the 'line-of-business participation' than 'governance, team leadership' should be called for. 


\section{Theoretical contribution}

The research project aims to integrate theories from organizational design, and organizational psychology with practically inter-relating several state-of-the-art business and research problem domains. This article provides in-depth integration of the constructs relating to governance, leadership, and innovation with the research of each other. The research followed the practice of establishing the empirical linkage between two constructs and to establish the third construct as a potential mediator in between that would offer new potential relationships. The study deepens some of the existing theories by offering a new perspective light on their real-world and state-of-the-art application: involvement theory of Swanson (1974), the stewardship theory of management from Davis et al. (1997), Brown and Magili (1994) with the principles of contingency theory, Bono (2003) and transformational leadership theory, strategic innovation from Krinksy and Jenkins (1997).

Only a few writers have been able to demonstrate structured research on data governance. The results from Alhassan et al. (2018) validate such identified research gap and concerns that the scientific publications on data governance almost exclusively focus on defining activities, and not on successful implementation. As many researchers have demonstrated that change agents play a major role in IT implementation success or failure and the need for strong leadership is a managerial practice (Harari \& Zeira, 1976; Kimberly \& Nielsen, 1975; Sofer, 1964), there are yet not many specifications of such leadership behaviours.

Furthermore, there is no evidence of any empirical connection of the topic with data compliance and innovation on the endogenous side, as well as team leadership 0 exogenous side neither constructs that operationalize particularly LOBSP, DCI and GTL. This study fills the research gap and examines the relationship between data stewardship leadership, business user participation, and data compliance innovation.

This work contributes to addressing the research gap of scientific publications focused on data governance, successful implementation strategies and adds to prior literature with the categorization of interaction and empirical evidence in focal research domains.

\section{Method}

The focus of the research is exploration, causal modelling and theory building, rather than theory confirmation. As first-generation techniques, such as correlations, regressions, or difference of means tests (for instance ANOVA or t-tests), offer limited modelling capabilities, while second-generation techniques, covariance-based Structural Equation Modelling (SEM) or Partial Least Square (PLS) offer extensive, scalable, and flexible causal-modelling capabilities, the latter statistical method was selected. In particular, SEM and PLS allow for complex models that include latent (unobserved) variables, formative variables, chains of effects (mediation), moderation, and multiple group comparisons of these more complex relationships (Lowry \& Gaskin, 2014). 


\section{Structure}

This study is composed as follows. After this introduction, there is a beginning of the theoretical background with a review of the governance team leadership, line-of-business stakeholder's participation, and data compliance innovation. The next one is a chapter on the research model and conceptual framework followed by the chapter on research method, including data collection, operationalization, and instrument explanation. Discussion section gives details on the results obtained. And this works ends with a conclusion and summary.

\section{Theoretical Background}

A holistic approach is utilized to establish the theoretical background of the three constructs, integrating change management and leadership material determined GTL, while the body of knowledge of data governance and user engagement, involvement and participation formed LOBSP and eventually innovation, data management, and customer interaction created DCI. The following three sections, Governance Team Leadership (GTL), Line-of-Business Stakeholder Participation (LOBSP) and Data Compliance Innovation (DCI) contain such theoretical integration and provide justification for the conducted construct operationalizations used in quantitative research.

\subsection{Governance Team Leadership (GTL)}

Data governance is a companywide framework for assigning decision-related rights and duties in order to be able to adequately handle data as a company asset (Otto, 2011). More recent attention has suggested effective data governance as critical in obtaining utility from centralized data use, and data governance has been an emerging trend in enterprise information management (Cheong \& Chang, 2007). Much of the current practitioner's literature pays particular attention to the process of assigning individuals that communicate governance driven changes to data policy, regulations, and rules to their units/area, as well as that, develop rules for handling enterprise or domain data (Otto, 2011a). They are often called data stewards and are in the core of data governance organization. Data stewards are executors of governance programs. Davis et al. (1997) state that data stewardship can be derived from the stewardship theory of management as opposed to the agency theory of self-interested employees. Seen this way, Kooper et al. (2011) note that stewardship is the willingness to be accountable for a domain of business information for the benefit of the enterprise

Similarly, those that have some level of responsibility, though not necessarily authority, over data they define, produce and use - are normally called operational data stakeholders. They can be involved in any of the efforts of data entry, production, data integration, and analysis. In such setup, data stewards would co-exist and cooperate with operational data stakeholders participants from the line of business and would be normally appointed, one per business unit or department (Wende, 2007). Therefore, the concept of operational data stakeholders in this work is further referenced as line-of-business stakeholders.

While relating these two groups, the concept of leadership needs to be integrated into such operational model of data governance stewards team and the way how they are 
approaching line-of-business stakeholders - in order to manage change and change resistance.

A decision on leadership integration is consistent with one of the tracks in organization change management - the strategic choosing theory highlights leadership and leaders (managers) as the real actors of the change process (Child, 1997). Weber et al. (2009) argue that effective and high-quality data governance is possible only if it also becomes part of the corporate culture where business stakeholders and managers play a crucial role in institutionalizing it and requires organizational change. McNuilty (1962) indicated the significance of communication structure in the change process while Kimberly and Nielsen (1975) suggest that proactivity in changing employees behaviour is an inhibitor for proceeding with organizational change. Seen as control discipline and set of decisions that define expectations, grant power, or verify performance - governance triggers high levels of resistance (Berson \& Dubov, 2011). Even realizing and acknowledging the costs of their data problems, many firms as a result of it primarily resist and just continue to operate in silos. There is too strong fear that bringing data management closer to cross line-ofbusiness perspective comes with pain, conflicts, political battles, differences of opinion and additional workload (Seiner, 2014).

Following the need for leadership addressing change management resistance, two concepts were taken that intersect with leadership theory, building team identity and knowledge sharing and communication.

Data governance stewardship team members need to have and emit high team identity and some of the transformational leadership abilities for an efficient span of governance, considering change resistance in such projects. Superordinate identity definition can be applied to governance team - as a degree to which members identify themselves with the stewardship team and success of the team (Miller \& Brewer, 1984). Sherif (1988) supports this and describes that utilization of super-ordinate goals boosts cooperation between culturally different groups. In their proactive leadership driven cross-functional work data stewards foster positive relationships with other teams and their leaders - making their group perceived positively outside (Simsarian Webber, 2002). This way utilized such team identity serves governance program initiation, progress, and expansion through increased participation of line-of-business stakeholders. Emitting outside such self-concept-driven motivation commences share of information, more attention to each other's perspectives during decision-making, and constructive approach in dialogues (Maltz \& Kohli, 2000).

Pinto et al. (1993) outline that there is a record that the success of cross-functional teams comes to their proactive engagement in valuable communication, cooperation and coordination team processes. Initiation of structure' comes from leadership literature and is defined as the extent of proactive assignment of tasks and prescription of behaviours given by the governance team, in order to achieve the desired results and reaction and participation from line-of-business stakeholders (Wofford \& Liska, 1993). The structure would facilitate the creation of recurring communication patterns in data stewardship governance teams. Consistently with this, Magpili and Pazos (2018) claim that structure clearly and explicitly states goals and task descriptions. Likewise, Porter and Lilly (1996) argue that influencing team member behaviour by structuring the environment surrounding 
the task reduces cases of dysfunctional communication and enhances conflict resolution in teams. Using structure initiation, stewards are able to influence the line-of-business stakeholders individual and collective accountability as it improves communication and understanding among team members. Governance is seen as complex in its initial reconciliation phases and the more complex and ambiguous tasks; the more important structure initiation is (Sarin \& McDermott, 2003).

\subsection{Line-of-Business Stakeholders Participation (LOBSP)}

In this paper, the concept of operational data stakeholders from the previous section is applied, line-of-business users. Data governance provides values to traditional information management (IM) particularly through its ability to involve and align with business stakeholders, besides cross-functional links that governance eventually provided to IM and beside it brought evolving nature to IM due to more extensive metrics usage. The LOBSP can also be seen as part of wider research domain of IT - business alignment, that has a high association with financial performance. The alignment that IT and business strategies generate a sustainable competitive advantage and increase profitability (Kearns \& Lederer, 2003). Their participation in the governance program is a vital source of many necessary system information, due to their knowledge of the nature of the work that the system is supposed to support (Hendry, 2008). Likewise, Bano and Zowghi (2015) suggest that users typically have significant knowledge of the application domain, the tasks they perform, work practices, the context of the system use and their behaviour and preferences.

In literature, participation is associated often with responsibility. To assess participation with individual responsibilities and influence, there are even measures developed by Baroudi et al. (1986). Correspondingly, Silvola et al. (2011) illustrate that uncertain data ownership might result in inadequate process definitions, affecting data maintenance problematic or even impossible. Wende (2007), outlines the importance of historical experience that If accountabilities are not assigned to line-of-business owners and are assigned to IT departments - the problem resolution ends up in simply implementing another technically oriented data management systems.

Moreover, several attempts have been made in the literature to associate user participation with governance in setting objectives and its evaluation. For instance, Knolmayer and Rothlin (2006) state that the process owner must participate in setting measures in order that the relationship between business processes and data becomes evident to each and every party. Similarly, Vaygan et al. (2007) argue that without proper involvement of line-ofbusiness stakeholders in setting and reviewing its measurement, major data do not have sufficient quality. Data relationship inconsistencies impact the ability to identify relations between business entities. They come from different definitions across applications footprint and across lines of business (Berson \& Dubov, 2011). If requirements for data standards, quality are undocumented and unstandardized and if the line-of-business owners didn't support the identification of data capture, maintenance, and usage process flaws - the IM initiative does not deliver results. That's why formal engagement, which assumes their responsibility (identify data to be governed, rules, policies, follow-up) is necessary. Likewise, Villar (2009) notes that business representatives role must in the centre of governance model one as critical data should be assigned to those who can apply business judgments. 


\subsection{Data Compliance Innovation (DCl)}

Customers of every data processing economic entity will certainly expect from their data holder compliance with GDPR. Therefore simply fulfilling this expectation is not in any way, gaining a competitive advantage. On the other side, response to compliance request this time might be used to engage with customers in a new way and to innovate in that way. For Sawhney et al. (2005), the changes are an opportunity for interaction where businesses can acquire greater insights into their customers' needs. However, a well-functioning governance program, with line-of-business participation and proactive leaders (stewards) is required. Accordingly, the paper attempts to integrate innovation, customer interaction and data compliance literature.

Boer et al. (2001) report that innovation theory is an established area of research, which in further stages handed over its popularity to some of its subareas such is continuous innovation. Similarly, there is also the direction of strategic innovation that aims to actively participate in shaping markets and external trends, rather than just reactively adapting to external trends (Kim \& Mauborgne, 1997). Furthermore, Zaltman et al. (1973) propose initiation and implementation as two diverse phases of the innovation process, highlighting the strength of having an openness to the innovation as the basis for the former one.

For Burns and Stalker (1994), the vital ability of the organization to adopt or implement new ideas, processes, or products successfully is its capacity to innovate. Market orientation and customer focus have been often related to innovation work. Kimberly and Evanisko (1981) recommend a focus on innovation (implementation of new ideas, products, or processes) rather than learning (development of knowledge and insights) as a model of market orientation. (Wang \& Chung, 2013). Consistent with this is the amount of studies that discovered that firms with a customer focus tend to be more proactive in meeting customer needs and that, when measured, customer orientation has a positive impact on innovation.

Linking customer engagement and interaction with innovation is known in research. Economic, political and social activities are moving online - changing the interaction between individuals, businesses, and government, giving wide scope for innovation. Contribution to commercial success comes from the increased interaction mixed with the usage of granular analytics in parallel. For instance, such platform may provide dynamic pricing correlated with risk data, ad hoc, and is winning strategy in a price sensitive, competitive landscape, if it is based on accurate and real-time insights (Mantelero, 2014). Data can be used to attract more users, who then generate more data, which helps to improve services, which attracts more users. Ritter et al. (2002) state that effective interactions with suppliers, customers, and other organizations - as network competence will always lead to competitive strength and performance.

Eventually, some authors already related data compliance and governance from one side and innovation and customer interaction from another. Kumar et al. (2010) outline that adaption of a customer-centric engagement model alongside compliance-driven activities is in the strategy of adding more value to the data returned and displayed in data compliance 
related requests. However, as Acquisit et al. (2016) note - GDPR is also a vehicle and platform for agreements on business-to-consumer data utility and privacy trade-offs and such channel raises high requirements for data governance controls of interactions. Granular governance measures of data and management of customer personal data with extreme caution lead to innovation, services, and ideas on how to make the customer happier. Organizations can improve the customer experience by triggering more relevant interactions. On the top of that working collaboratively together with the customer produces a richer and more valuable dataset of their interaction, which if used properly can help to build trust and confidence (Burgoon et al., 2015). Sustained personal engagement and ongoing success in exceeding customer expectations will generate loyalty.

\section{Research Model}

Initial reaction to the term data governance is often resistance and concern that it will include a surpassing amount of new policies, laws or rules about the relationships people have with data and that will radically interfere with existing responsibilities, while threatening the existing work culture and being initiative over and above normal working hours and work efforts, (Seiner, 2014). Governance stewardship team becomes centre of high demands on leadership, communication, knowledge sharing and collaborating skills that will provide them with the ability to influence, both business and technology teams across business units (Villar, 2009). Different business units protect by inertia their own distinct data management practices and processes developed over the years. An only a structured and proactive approach to change of organizational practices and leadership driven change management may interrupt this rigid structure and increase the responsibility of business stakeholders. Fortunately, means of data governance provide finally a process and structure to the holistic information management initiatives, that leadership can bank on (Vilminko-Heikkinen \& Pekkola, 2017). Likewise, Plotkin (2013) suggests that a successful data steward role requires leadership, organizational, and facilitation skills, that will drive setting up and leading meetings, collaborating with others, following up on issues and embed the habit of producing of measurable outcomes in the line of business stakeholders data culture. Initiation of structure adopts the use of rules, directives, and routines, exactly as mechanisms in integrating tacit knowledge embedded in individuals (Grant, 1996). Consistent with this, Thamhain (2007) outlines that the absence of task structure ruins the process where team members clearly understand their roles and responsibilities, which is the main obstacle to the success of cross-functional teams.

Several studies have reported the advantages of overruling the line of business resistance by creating a solid sense of leadership driven cross-functional superordinate identity, impacting the success of the overall project. This method impacts line of business stakeholders strong functional group identities and enriches the effectiveness of their communication with data governance stewardship team (Sethi, 2000). Similalry, Ford and Randloph (2016) illustrate that with their identification and commitment, stakeholders eventually rise above their functional areas, where they are deeply grounded by source teams evaluation and reward influence. Their increased involvement in the outcome and results of the governance program creates interdependence and cooperative frame of mind. Otherwise, business process owners do not even recognize their role as responsible for 
data associated with their own processes, even doubting their, skills expertise and ability to contribute to the project (Silvola et al., 2011).

Therefore, it is hypothesized: line-of-business participation in governance program is positively impacted by the leadership of the team of data steward $(\mathrm{H} 1)$.

Boer et al. (2001) find that for continuous innovation it is necessary to be disciplined in an aim for ongoing ability to configure and re-configure business processes, procedures, outcomes, results, people, technologies and organizational arrangements, and this can be done by line-of-business stakeholders. Developing culture of continuous curiosity and questioning of an overall view of the business by business stakeholders, involving ideas and beliefs about the customers, and technology - is a precondition for strategic innovation (Kim \& Mauborgne, 1997). Burns and Stalker (1994) argued that decentralized organizational design, with fluid responsibilities moving from functions towards centralized programs and back, would lead to cooperation and share information (Miles \& Snow, 1992) and therefore to innovation. Likewise, Gupta and Govandarajan (1991) believe that mechanisms such as cross-unit committees with participation from each line of business, integrator roles, and matrix structures intrigue information sharing and discussion. Without line-of-business stakeholders participation - data attributes that describe business entities (product names, total revenue) often contain different values for the same attributes across different applications and functions - impacting confidence and trust of in innovative ideas coming from data insights (Berson \& Dubov, 2011). Data compliance regulations, such is GDPR, open up a new channel for customer interaction, which might be utilized as a customer engagement vehicle. To sustain innovative strategies in customer engagement, the requirement for any content-channel mapping is to origin from traceable, authoritative data governed by process owners within line-of-business (Buckley et al., 2014; Moormann \& Palvolgyi, 2013). Purely IT-driven concepts of data quality that do not include the business view, lack the strategic focus on data measurement, outcomes and results (Otto, 2011). The governance tier that ensures higher user engagement leads to data being more shared across departments and data domains triggering creative thinking and innovation. Organizations with governed data state higher accessibility of data that attacks line-ofbusiness users. Leenheer et al. (2010) explain that through increased accessibility and usage governance becomes a driver of increased information flows within the organization. Similarly, greater data utility comes from higher usability and a wider span of data. Governance-participation-driven traceability of customer data improves further usability across segments, especially these customer-centric units that aim to increase the relationship with and experience of the particular customer. This generates new ideas on revenue generating customer engagement. High participation in making decisions increases involvement and the commitment to innovate (Damanpour, 1991), boosted information flow and communication up and down rise innovation (Kanter, 1983), support and collaboration that encourages new ideas and risk-taking as lessens fear (Pierce \& Delbecq, 1977).

For that reason, it is hypothesized: line-of-business stakeholders participation in the governance program positively impacts data compliance innovation (H2). 
Companies processing the personal data of data subjects in the EU review their existing policies, procedures, and practices and require an enterprise approach to the 'customers data' asset. This can evolve into a broader effort on eventually start utilizing enterprise data as a service to support the speed and scale at which customer-facing functions will have to operate to be competitive. This would be possible with the strategy of continuous innovation in customer interactions, supported by an increased line of business stakeholders participation from strong governance leadership driven program. A strategy of strengthening the customer dimension of the organization and assembling well functioning horizontally and vertically integrated groups of process owners leads to greater leverage of the existing knowledge of the data about customers that lies within line-of-business and integrates this knowledge (Komssi et al., 2015). Underneath must be a framework of proactive, measurable, collaborative and leadership-driven governance organization with the stewardship team in its centre.

\section{Figure 1 | Research Model and Hypothesis}

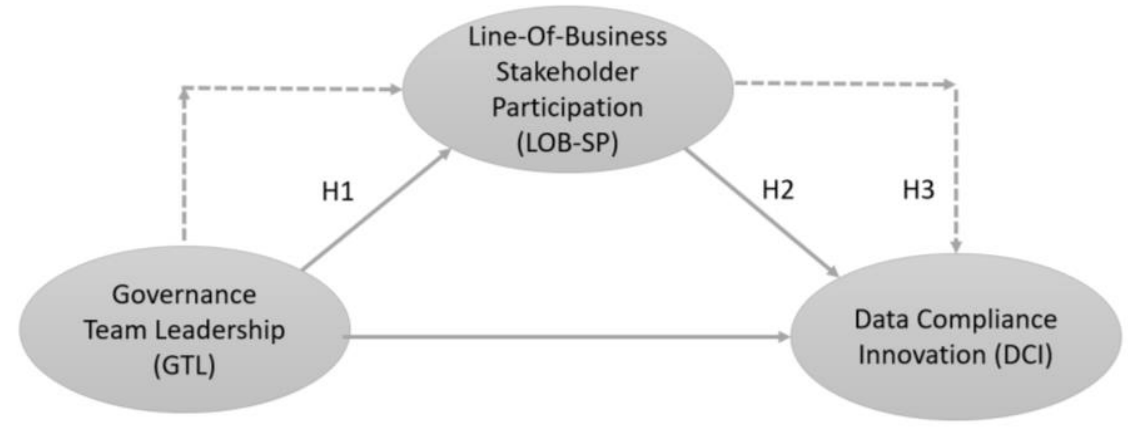

Source: authors

Hurley and Hunt (1998) argue various characteristics of a firm's culture, such as an emphasis on learning, participative decision making, support and collaboration, and powersharing, affect whether the firm has an innovation orientation. Capacity to innovate is influenced by the ability to have a single view, for instance, on customers. This way, an organization can identify and develop processes that help to discover and resolve inconsistencies and incompleteness caused by different business units and require unit representatives participation. Governance framework would use their participation to address challenges that different business units often use the same data attributes to describe different entities. Inconsistencies in attribute-level data often go hand in hand with the poor data-related business rules on the way that data has to be formatted, translated, and used (Berson \& Dubov, 2011). Lack in single versions of the truth in non-governed data without governance team leadership and without line-of-business participation - makes difficult to understand those customer engagement factors and trends that may affect the business, as well as the process of gaining better insight into the customers' goals, demands, abilities becomes stiff. This is followed by the unlikelihood of definitions of more attractive and compelling product or service, based on deeper observations of customer's 
behaviour (Seiner, 2014). Correspondingly, it is also hypothesized: there is a mediating effect of line-of-business participation on the relationship between governance team leadership and data compliance innovation $(\mathrm{H} 3)$.

All three hypotheses and research model are represented in Figure 1

\section{Data and Methods}

Based on Webster and Watson (Webster \& Watson, 2002) a literature review has been conducted in order to identify relevant literature, discussing data governance line-ofbusiness participation and governance team leadership, and data compliance innovation. The quantitative questionnaire is developed for variables as none is found for LOBSP, GTL, and $\mathrm{DCl}$, after a rigorous literature review. Structural equation modelling (SEM) is used as a statistical method that refers to analyzing path models with latent variables, where Partial Least Square (PLS) indicates path models analysis particularly with indirectly measured variables (measured through other variables) (Chin, 1998; Kock \& Hadaya, 2018).

\subsection{Data Collection and Sampling}

Survey method is employed to collect data for analysis and empirically test the proposed model of this study. Whenever sample size requirements are met, surveys are useful in answering many questions regarding an event in Management IS area (Pinsonneault \& Kraemer, 1993). The survey was hosted using SurveyMonkey.com online platform. The first page served as a tutorial page with a consent form outlined the purpose of the research, confidentiality, and researcher contact information.

Data collection was administrated during December 2018. 147 responses were collected, from which 98 were completed (completion rates of $66 \%$ ). Participants for the full study research were recruited directly by authors from Linkedln. 10 participants, data governance experts from Oracle Corporation and IBM and PhD candidates from the University of Economics in Prague, gave feedback on the survey and minor modifications were conducted. This was extended into a pre-test of 30 participants, which confirmed overall validation of the proposed model.

Responses are asked from senior members associated with data management, governance or compliance teams (internal leaders or external partners/consultants). These are enterprises that process data about customers and have data governance teams. Data governance teams are set in organizations of a bigger size that process a larger amount of data. Therefore, 8 vertical categories were selected: Financial Services, Telecommunications, Aerospace or Transportation, E-Commerce or Retail, Technology, Software or Internet, Consulting, Healthcare. The total number of targeted profiles identified in targeted regions and industries is above 2000. The European Union countries were grouped into 4 categories: Western, Southern, Northern and Central Europe and an additional category of firms outside of $\mathrm{EU}$ and sampling were stratified across these 4 regions and then it was randomized per industries in that particular region. Central Europe assumed the following countries: Germany, Austria, Czech Republic, Slovakia, Poland, Hungary, and Romania. 
The "10-times rule" method is the most broadly used minimum sample size estimation method in PLS-SEM (Hair, 2013) (Peng \& Lai, 2012). Kock and Hadaya (2018) offered inverse square root method, where bmin is the lowest recorded statistically significant value of the path coefficient value in the model and $\operatorname{ROUNDUP}\left((2.486 / \mathrm{bmin})^{\wedge} 2\right)$, where bmin is the name of a cell that stores the value of $|\beta|$ min. The direct relationship that records the lowest statistically significant path coefficient value in the model is LOBSP - DCI $(0.319)$. Thus, 61 is the minimum required sample size according to $\operatorname{ROUNDUP}\left((2.486 / 0.319)^{\wedge} 2,0\right)$.

The diversity of employees is especially important in case of the relations considered in this paper since all analyzed variables are highly susceptible to the job position of a respondent.

\subsection{Operationalization and Measurement Instrument}

To avoid scale proliferation, when possible, existing scales were consulted (Bruner, 2003). Once the survey items were determined, the procedures suggested by Dilman (2007) for survey design were employed. The scales had to be adapted due to change in construct generalization hierarchy and the reassignment of different content areas to the construct and amount of items had to be dropped (Finn \& Kayande, 1997).

In rationalizing the existing constructs and developing the measures for the adapted new constructs - the external knowledge sources from consulting companies were utilized while maintaining a relation to original concepts.

In developing the measures, mentioned adaptation to the focal concepts of this research took place (Line-of-Business Stakeholders Participation (LOBSP), Governance Teal Leadership (GTL), Data Compliance Innovation (DCI)) while maintaining original concepts (Manager Involvement (Vanlommel \& Brabander, 1975), Structure Initiation (Sarin \& McDermott, 2003), Superordinate Identity (Sethi, 2000), Degree of Innovation (Sarin \& McDermott, 2003) and Interaction Orientation - Interaction Response Capacity (Ramani \& Kumar, 2008). This study argues that LOBSP is a special case of Manager Involvement, The work assumes that integration of subsets of constructs of Structure Initiation and Superordinate Identity can produce operationalization for GTL, while Degree of Innovation and Interaction Orientation integrated to form a question for $\mathrm{DCl}$.

The measures on Interaction Orientation from (Ramani and Kumar 2008) are adapted for $\mathrm{DCl}$, where sub-construct measures for Interaction Response Capacity had four questions and for Customer Empowerment contains three questions. IN-1 is an integrative dimension made from the question related to product-related innovations concepting in Interaction Response Capacity combined with the question in Customer Empowerment related to having systems in place that record each customer's transactions. Other questions were not applicable in the context of this research as they were too specific to the research in the field of marketing and are not easily generalized to the case with utilizing customer interaction in case of GDPR compliance.

The measures on Manager Involvement (Vanlommel \& Brabander, 1975) are adapted for LOBSP, where the original operational definition of the conduct had three indicators, related to design, implementation, and follow-up. LOBSP1 is an integrative dimension made from the first two indicators of Manager Involvement, where the formulation of objectives 
reference is taken from the first and statement on the engagements to assume responsibility is taken from the second. LOBSP2 is a representation of the third indicator where the evaluation of results and control on the use of system outputs operationalizations are utilized. Other expressions from the original construct were not applicable in the context of this research.

To measure GTL, the relevant portions of two previously validated instrument were utilized. Adapted are two out of four items from the Structure Initiation - Process Structure construct (Sarin \& McDermott, 2003) (items related to scheduling the work to be done, and maintaining definite standards of performance) and one out of five items of Structure Initiation - Goal Structure construct from the same instrument (item about letting the team know what is expected of them). All three resulted items were integrated into one, and this formed GTL1. One out of five questions of the construct Superordinate identity (Sethi, 2000) is also adopted (an item about behaving like a unified team). This is how GTL2 was formed. The other questions were not relevant to the research of data stewards leadership.

Five-point Likert-type scales were used (e.g., 1=strongly disagree to 5=strongly agree) and consistent with standard practice, ordinal data has been treated as continuous data in order to facilitate interpretation (Flora \& Curran, 2004). It is important that the scale used generates sufficient variance among respondents for subsequent statistical analysis, and this is the case with the Likert scale (Hinkin, 1995).

\section{Results and Discussion}

This section combines data analysis, hypothesis testing with a contribution, limitations, and suggestions for further research.

\subsection{Data Analysis}

Podsakoff et al. (2003) suggest that to deal with common method variance data collection procedure was in this research was designed in a way that respondents' anonymity was protected. There was no request for data that can identify the firm or respondent. An IP address is not tracked, neither whether or an invited target profile participated in the study.

The model can be considered free of common method bias as all Variance Inflation Factors (VIFs) resulting from a full collinearity test are equal to or lower than 3.3, having 1.34 as the highest in the inner model VIFs of this research (Kock, 2015), which proves as well that there is no problematic multicollinearity in the model.

As per Hair et al. (2017), normality test in SmartPLS is via interpretation of Excess Kurtosis and Skewness and this model has no value greater than +1 or lower than -1 , and shows no evidence of substantially skewed or too peaked or flat distribution.

Meyers et al. (2013) describe that test for univariate and multivariate outliers was conducted, and no outliers were identified. In order to find univariate outliers, a z-test was conducted, and no case is identified to have $\mathrm{z}$ scores with extreme absolute values greater than the critical value of 3.29. Moreover, the data were examined for multivariate outliers using the Mahalanobis Distance approach. The chi-square test is applied $(p<.001, d f=1$, where 1 as the degree of freedom equals the number of independent variables) to 3 
composite variables and there were no cases appeared to have chi-square statistics greater than the critical value of 26.125 (Meyers et al., 2013).

The measurement model conducted three evaluation steps: individual item reliability (indicator reliability), construct reliability and construct discriminant validity. Indicator reliability was assessed via item loadings and corrected item-total correlations. All items passed the threshold value of 0.4 for item loadings (Hair et al., 2017).

An item-total correlation test is performed to check if any item in the set of tests is inconsistent with the averaged behaviour of the others, and thus can be discarded. (Churchill, 1979). There was no item-total correlation found with lower than 0.2 or 0.3 value and no signals that the related item does not correlate very well with the scale overall and, thus, it may have potential to be abandoned (Anthony, 2003).

Reliability and validity check is conducted for the converted data. At a high level, validity refers to the capability to measure the right concept. Reliability is the accuracy in measurements when the measurements are repeated.

Construct reliability was tested through three criteria: Cronbach's $\alpha$, Composite Reliability $(\mathrm{CR})$ or internal consistency reliability, and Average Variance Extracted (AVE). The results show that Cronbach's a values met the critical value of 0.7. Additionally, CR and AVE values are higher than the suggested value of 0.7 and 0.5 , respectively (Chin, 1998) (Fornell \& Larcker, 1981). Thus, sufficient construct reliability was demonstrated.

The measurement model validity was tested with discriminant validity through Confirmatory Factor Analysis (CFA). A matrix of item-loading was constructed in order to conclude that each item loads on its latent construct stronger than other latent constructs (Chin, 1998).

A latent variable correlation matrix was created in which the diagonal line represents the square root of AVE values (Fortner-Larcker criterion in SmartPLS). These values are greater than each correlation value on the associated row and column (Chin, 1998).

The explanatory power of the model was evaluated via the coefficient of determination or Rsquared. The acceptable R2 value of 0.254 indicates that only $74.6 \%$ of the variance in LOBSP was left unaccounted by the independent variables. The R2 value of $\mathrm{DCl}$ is 0.09 and is weak according to (Chin, 1998). However, low R2 values still indicate a real relationship between the significant predictors and the response variable. There are additional predictors that increase the true explanatory power of the model which are not reported in this study, as this is not a major purpose.

The goodness of fit (GoF) has been developed as an overall measure of model fit for PLSSEM. However, as the GoF cannot reliably distinguish valid from invalid models and since its applicability is limited to certain model setups, researchers should avoid its use as a goodness of fit measure. The GoF may be useful for a PLS multigroup analysis (PLSMGA). Variance SEM methods such as PLS do not support model fit indices such as Chisquare, Adjusted Goodness of Fit (AGoF), Normed-Fit Index (NFI), and Comparative Fit Index (CFI) (Chin, 1998). 
The standardized root mean square residual (SRMR) based on transforming both the sample covariance matrix and the predicted covariance matrix into correlation matrices - is defined as the difference between the observed correlation and the model implied correlation matrix. Thus, it allows assessing the average magnitude of the discrepancies between observed and expected correlations as an absolute measure of (model) fit criterion. A value of less than 0.10 is considered a good fit. Henseler (2016) explains SRMR as a goodness of fit measure for PLS-SEM. This model records 0.069 .

Applying the formula of Henseler et al. (2009), the Q2 value resulted in a good model fit of $0.112>0$, as per Esposito Vinzi et al. (2010), 0.02, 0.15, 0.35 are considered as a weak, moderate and strong degree of predictive relevance of each effect.

Effect size also assesses the strength of a model as it reflects the statistical power of the relationships in the population (Hair et al., 2009). To calculate effect sizes, the f2 formula by (Chin, 1998) is applied. According to (Cohen \& Bailey, 1997), $0.02<\mathrm{f} 2 \leq 0.15,0.15<\mathrm{f} 2 \leq$ 0.35 , and $\mathrm{f} 2>0.35$ are considered small, medium, and large, respectively. Results are $0.341,0.084,0.002$. The low value was expected for CFI variable where the effect of GTL is hypothesized the only trough is mediating variable LOBSP.

\subsection{Hypothesis Testing}

To test the hypotheses, partial least squares (PLS) in SmartPLS is used where a standardized regression coefficient gives us a mixture of a (causal) effect and the distribution of a variable.

\section{Figure 2 | Hypothesis Testing Results}

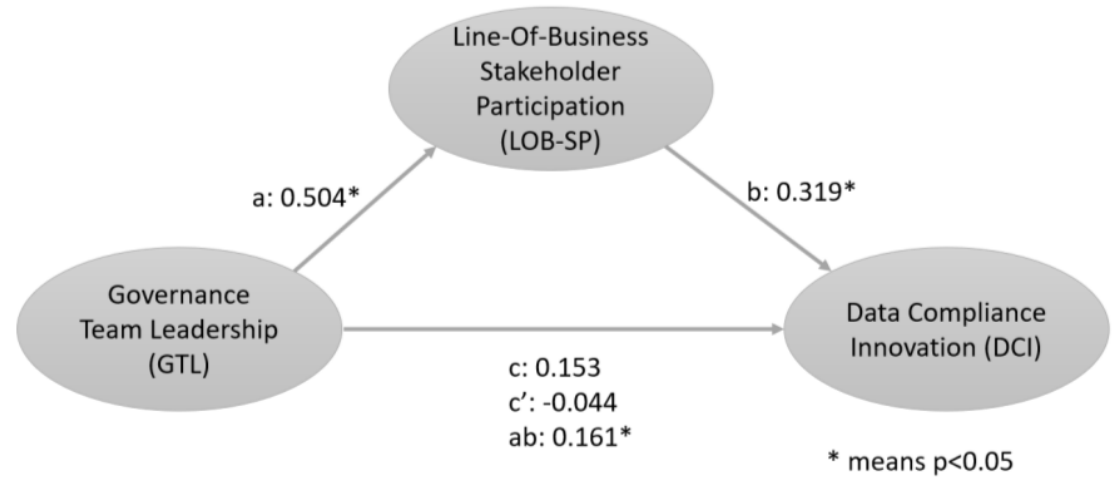

Source: authors

Research findings show that Governance Team Leadership (GTL) positively impacts Lineof-Business Stakeholder Participation (LOBSP), with significant standardized path coefficient $(\beta=0.50, p \leq 0.01)$, (LOBSP) Line-of-Business Stakeholder Participation in governance program positively impacts Data Compliance Innovation (DCl) $(\beta=0.32, p \leq$ 0.05). Therefore, this leads to acceptance of $\mathrm{H} 1$ and $\mathrm{H} 2$. 
Hair (2013) describes the systematic mediator analysis process in PLS-SEM in more detail as well as (Nitzl et al. 2016). Full mediation is shown if the relationship between independent and dependent variable is not significant, and both relationships, independent variable - mediator variable and mediator variable - dependent variable, are significant.

GTL impact on DGI is not significant, standardized path coefficient $(\beta=-0.044, p=0.73)$, while both other relationships are significant, GTL impacts LOBSP $(\beta=0.50, p \leq 0.01)$ and LOBSP impacts $D G I(\beta=0.32, p \leq 0.05)$. In SmartPLS, the results of the PLS-SEM algorithm and the bootstrap procedure include the specific indirect effects these outcomes permit conducting a mediator analysis (e.g., as suggested by Hair (2013)). This effect for GTL-LOBSP-DGI specific indirect effects is 0.16 with $p \leq 0.05$. Further, this study also demonstrated that LOBSP has a mediation effect as it reduced the coefficient value between GTL and DCl from 0.15 to -0.044 . Therefore, research findings show that there is a mediating effect of line-of-business participation on the relationship between governance team leadership and data compliance innovation. Thus H3 is accepted.

The testing results for all three hypotheses are represented in Figure 2.

A number of demographic questions were asked by the participants. 20 out of 98 firms (20\%) of the observed companies were in Central Europe. GTL1 and IN1 were the lowest across all regions (3.25) compared to all-regions-average of $3.44,2.85$ compared to allregions-average of 3.00). LOBSP1 and GTL2 were the second lowest compared to allregions-average (3.75 and 3.15 respectively). Governance Team Leadership scored the lowest in CEE, as well as GDPR Data Compliance Innovation, where the former showed more shows more severe difference (Figure 3).

\section{Figure 3 | Mean Values Per Regions}

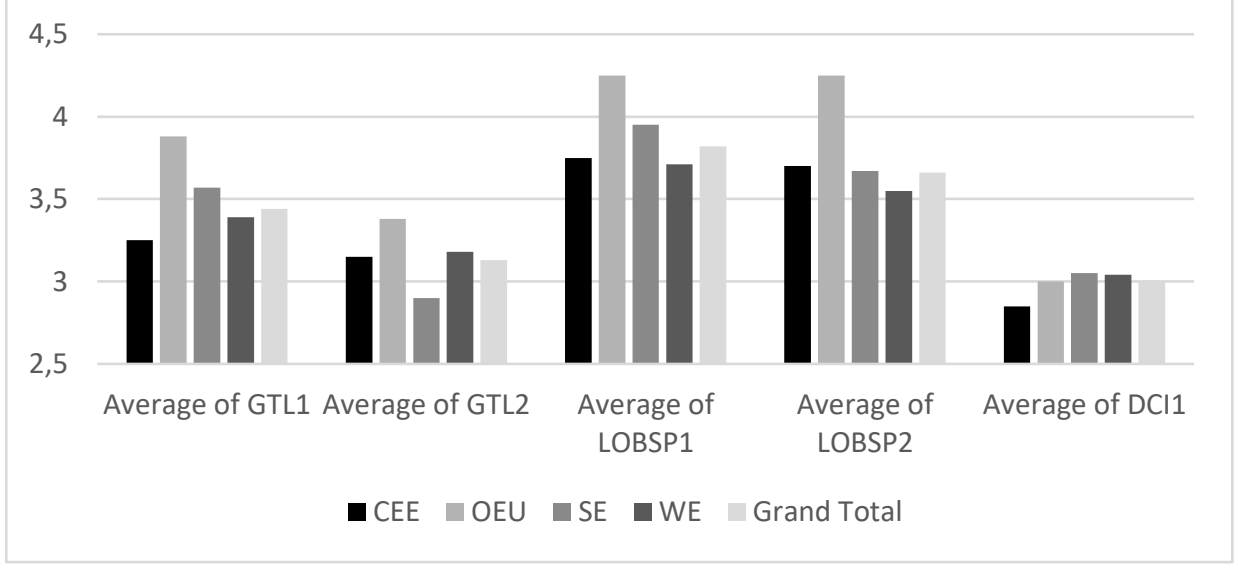

Source: authors

\subsection{Contribution, Limitations and Further Research}

The present study makes several noteworthy contributions to integrating varies bodies of knowledge, information governance with change management and leadership theories, as well as innovation. It adds to the stewardship theory of management, with the first empirical work related to data governance stewards and integrates it with the strategic choosing 
theory in leadership. The empirical findings from this study make several contributions to the current literature. These findings enhance our understanding of elements of business impact when it comes to data governance teams, in particular with its relation to innovation - an important category of competitive advantage. The study has gone some way towards enhancing our understanding of strategies to make data governance implementations successful. Transformations triggered by technology innovations that bring to the business their undoubted and proved value still need to be prioritized in research from the perspective if they are easily adopted or if the organization is experiencing difficulties in such process. Identified as factors of impact, line-of-business stakeholders involvement and governance team leadership, assist in our understanding of the required phases on the road towards innovation during data compliance projects.

The findings in this report are subject to at least three limitations. First, as per Idaszak et al. (1988), reverse-scored items are not used to reduce response pattern bias. This is due to the intention to minimize the number of items and due to its potential to introduce systematic error to a scale, as stated by Jackson et al. (1993). Second, the number of items in a measure of constructs is low as the measure was intended to be short is an effective means of minimizing response biases (Schriesheim \& Eisenbach, 1995) and to avoid that scale lengths affect response rate (Roznowski, 1989). Targeted roles serve as high profiles and managers, without low intention to spend time in online surveys. Constructs are accurately described and made clear when measured with a single-item measure (Sackett \& Larson, 1990). There is an operational definition prior to a question in the survey.

The research objective is to get an overall judgment, a general view of the construct or impression of it and single-item measure is often adequate for the purpose as per Poon et al. (2002). However, scales with too few items may lack content and construct validity, internal consistency, and test-retest reliability and this remains limitation (Kenny, 1975). Third, due to the is a change of in this hierarchy of generalization and reassignment of different content areas to the construct was adapted from original ones, and that needs to be taken with caution.

Further experimental investigations are needed to estimate many elements in the study e. g. what are the mechanisms for establishing leadership in data stewards teams, risks of having attrition of line-of-business participation after initial pick-up or what are different innovation aspects in different verticals. Also, the research does not investigate further insights into descriptive statistics data shown for the Central European region and where the difference is coming from compared to other EU regions. This is an important issue for future research.

\section{Conclusions}

To prepare for the upcoming data revolution, companies need strategies for achieving a competitive advantage, where their associated benefits exceed their costs to maintain data and comply. Straightforward compliance with GDPR is expected by default and as such, makes no differentiation on the market.

All research questions are addressed. Proactivity and leadership od data stewards in the governance team and increased participation from line-of-business stakeholders lead to 
innovation in data compliance projects. Leadership in governance team leads to an increase in participation from line-of-business stakeholders - which is at the same time underlying mechanism of governance team leadership - data compliance innovation relation.

This research offers a 'line-of-business participation' as a management tool to increase innovation in data compliance project. The study proves this in the GDPR regulation case. If it is necessary to increase the 'line-of-business participation' than 'governance, team leadership' should be called for. If it is necessary to increase the 'line-of-business participation' than 'governance, team leadership' can impact directly innovation in data compliance project. However, the underlying mechanism that explains such effect is participation from line-of-business stakeholders, and such increase in participation should be the primary decision that will lead to an increase in innovation.

Data has become embedded within nearly every department and business unit, and proper data governance, as an example of such initiative, requires organizational change, much more rigorous alignment with business users and model maintenance with forming one cross-functional unit - data stewardship team. Data stewards in governance teams should have a vision or data roadmap within the department, be leaders, motivate others to contribute and to believe in the vision, repeatedly search for the ways to progress from existing stage of data management and frequently suggest better ways how data are defined, produced, and used (Seiner, 2014). Obviously, they have a crucial impact on the increase of line-of-business participation of operational data stakeholders. Furthermore, this increases the level of innovation and leads to competitive advantage. As stated by Floyd and Wooldridge (1996), the flow of collaboration and communication across all functional and hierarchical boundaries leads to diverse and deeply participative processes and further to innovation success and this was empirically shown in case of collaborative governance program mapped to the data compliance project.

\section{Acknowledgement}

Supported by the Internal Grant Agency, University of Economics, Prague, Faculty of Business Administration - project "Organizational psychology and organizational design to support cross-LOB teams in achieving profitable trade-offs between opportunities and restrictions in processing of customer data" (F3/06/2018).

\section{References}

Acquisti, A., Taylor, C., \& Wagman, L. (2016). The Economics of Privacy. Journal of Economic Literature, 54(2), 442-492. https://doi.org/10.1257/jel.54.2.442.

Aladwani, A. M. (2001). Change management strategies for successful ERP implementation. Business Process Management Journal, 7(3), 266-275. https://doi.org/10.1108/14637150110392764.

Alhassan, I., Sammon, D., \& Daly, M. (2018). Data governance activities: A comparison between scientific and practice-oriented literature. Journal of Enterprise Information Management, 31(2), 300-316. https://doi.org/10.1108/JEIM-01-2017-0007.

Anthony, L. J. (2003). The Cambridge Dictionary of Statistics (2nd ed.) 200326B.S. Everitt. The Cambridge Dictionary of Statistics (2nd ed.). Cambridge: Cambridge University Press 2002. 
Bano, M., \& Zowghi, D. (2015). A systematic review on the relationship between user involvement and system success. Information and Software Technology, 58, 148-169. https://doi.org/10.1016/j.infsof.2014.06.011.

Baroudi, J. J., Olson, M. H., \& Ives, B. (1986). An empirical study of the impact of user involvement on system usage and information satisfaction. Communications of the ACM, 29(3), 232-238. https://doi.org/10.1145/5666.5669.

Berson, A., \& Dubov, L. (2011). Master data management and data governance (2nd ed.). New York: McGraw-Hill Professional; London: McGraw-Hill.

Boer, H., Caffyn, S., Corso, M., Coughlan, P., Gieskes, J., Magnusson, M., . . Ronchi, S. (2001). Knowledge and continuous innovation. International Journal of Operations \& Production Management, 21(4), 490-504. https://doi.org/10.1108/01443570110381390.

Bono, J. E. (2003). Self-Concordance at Work: Toward Understanding the Motivational Effects of Transformational Leaders. Academy of Management Journal, 46(5), 554-571. https://doi.org/10.2307/30040649.

Brodie, R. J., Hollebeek, L. D., Jurić, B., \& Ilić, A. (2011). Customer Engagement. Journal of Service Research, 14(3), 252-271. https://doi.org/10.1177/1094670511411703.

Brown, C. V., \& Magill, S. L. (1994). Alignment of the IS Functions with the Enterprise: Toward a Model of Antecedents. MIS Quarterly, 18(4), 371. https://doi.org/10.2307/249521.

Bruner, G. C. (2003). Combating scale proliferation. Journal of Targeting, Measurement and Analysis for Marketing, 11(4), 362-372. https://doi.org/10.1057/palgrave.jt.5740091.

Buckley, S., Ettl, M., Jain, P., Luss, R., Petrik, M., Ravi, R. K., \& Venkatramani, C. (2014). Social media and customer behavior analytics for personalized customer engagements. IBM Journal of Research and Development, 58(5/6), 7:1-7:12. https://doi.org/10.1147/JRD.2014.2344515.

Burgoon, J. K., Bonito, J. A., Bengtsson, B., Ramirez, A., Dunbar, N. E., \& Miczo, N. (2015). Testing the Interactivity Model: Communication Processes, Partner Assessments, and the Quality of Collaborative Work. Journal of Management Information Systems, 16(3), 33-56. https://doi.org/10.1080/07421222.1999.11518255.

Burns, T., \& Stalker, G. M. (1994). Management of innovation (New ed.): Oxford University Press, USA.

Cheong, L. K., \& Chang, V. (2007). The Need for Data Governance: A Case Study, Association for Information Systems ACIS 2007 Proceedings. Retrieved from http://aisel.aisnet.org/acis2007/100.

Child, J. (1997). Strategic Choice in the Analysis of Action, Structure, Organizations and Environment: Retrospect and Prospect. Organization Studies, 18(1), 43-76. https://doi.org/10.1177/017084069701800104.

Chin, W. (1998). The Partial Least Squares Approach to Structural Equation Modeling. Modern Methods for Business Research, 295-336.

Churchill, G. A. (1979). A Paradigm for Developing Better Measures of Marketing Constructs. Journal of Marketing Research, 16(1), 64. https://doi.org/10.2307/3150876. 
Cohen, S. G., \& Bailey, D. E. (1997). What Makes Teams Work: Group Effectiveness Research from the Shop Floor to the Executive Suite. Journal of Management, 23(3), 239-290. https://doi.org/10.1177/014920639702300303.

Damanpour, F. (1991). ORGANIZATIONAL INNOVATION: A META-ANALYSIS OF EFFECTS OF DETERMINANTS AND MODERATORS. Academy of Management Journal, 34(3), 555-590. https://doi.org/10.2307/256406.

Davis, J., Schoorman, F. D., \& Donaldson, L. (1997). Toward a Stewardship Theory of Management. The Academy of Management Review, 22(1), 20. https://doi.org/10.2307/259223.

Dillman, D. A. (2007). Mail and internet surveys: The tailored design method : with new internet, visual, and mixed-mode guide / Don A. Dillman (2nd ed. 2007 update). Hoboken, N.J.: Wiley; Chichester: John Wiley.

Duch-Brown, N. (2017). The economics of ownership, access and trade in digital data: Digital Economy Working Paper 2017-01. Retrieved from https://ec.europa.eu/jrc/en/publication/eur-scientificand-technical-research-reports/economics-ownership-access-and-trade-digital-data.

Esposito Vinzi, V., Chin, Wynne, Henseler, J., \& Wang, H. (2010). Handbook of Partial Least Squares. Berlin, Heidelberg: Springer Berlin Heidelberg. https://doi.org/10.1007/978-3-540-32827-8.

EU Commission. (2016). General Data Protection Regulation: Regulation (EU) 2016/679 of the European Parliament and of the Council of 27 April 2016 on the protection of natural persons with regard to the processing of personal data and on the free movement of such data, and repealing Directive 95/46/EC. Official Journal of the European Union, L119, 1-88.

Finn, A., \& Kayande, U. (1997). Reliability Assessment and Optimization of Marketing Measurement. Journal of Marketing Research, 34(2), 262. https://doi.org/10.2307/3151863.

Flora, D. B., \& Curran, P. J. (2004). An empirical evaluation of alternative methods of estimation for confirmatory factor analysis with ordinal data. Psychological Methods, 9(4), 466-491. https://doi.org/10.1037/1082-989X.9.4.466.

Floyd, S. W., \& Wooldridge, B. (1996). The strategic middle manager: How to create and sustain competitive advantage / Steven W. Floyd, Bill Wooldridge (1st ed.). San Francisco, Calif.: Jossey-Bass Publishers.

Ford, R. C., \& Randolph, W. A. (2016). Cross-Functional Structures: A Review and Integration of Matrix Organization and Project Management. Journal of Management, 18(2), 267-294. https://doi.org/10.1177/014920639201800204.

Fornell, C., \& Larcker, D. F. (1981). Evaluating Structural Equation Models with Unobservable Variables and Measurement Error. Journal of Marketing Research, 18(1), 39. https://doi.org/10.2307/3151312.

Grant, R. M. (1996). Toward a knowledge-based theory of the firm. Strategic Management Journal, 17(S2), 109-122. https://doi.org/10.1002/smj.4250171110.

Gupta, A. K., \& Govindarajan, V. (1991). Knowledge Flows and the Structure of Control within Multinational Corporations. Academy of Management Review, 16(4), 768. https://doi.org/10.2307/258980. 
Hair, J. F. (2013). A primer on partial least squares structural equations modeling (PLS-SEM). Los Angeles, California: Sage.

Hair, J. F., Hult, G. T. M., Ringle, C. M., \& Sarstedt, M. (2017). A primer on partial least squares structural equation modeling (PLS-SEM) (Second edition). Los Angeles, London, New Delhi, Singapore, Washington DC, Melbourne: Sage.

Harari, E., \& Zeira, Y. (1976). Limitations and Prospects of Planned Change in Multinational Corporations. Human Relations, 29(7), 659-676. https://doi.org/10.1177/001872677602900704

Hendry, D. G. (2008). Public participation in proprietary software development through user roles and discourse. International Journal of Human-Computer Studies, 66(7), 545-557. https://doi.org/10.1016/j.jhcs.2007.12.002.

Henseler, J., Hubona, G., \& Ray, P. A. (2016). Using PLS path modeling in new technology research: Updated guidelines. Industrial Management \& Data Systems, 116(1), 2-20. https://doi.org/10.1108/IMDS-09-2015-0382.

Henseler, J., Ringle, C. M., \& Sinkovics, R. R. (2009). Advances in International Marketing (Vol. 20). Bingley: Emerald Group Publishing. https://doi.org/10.1108/S1474-7979(2009)0000020014.

Hinkin, T. R. (1995). A Review of Scale Development Practices in the Study of Organizations. Journal of Management, 21(5), 967-988. https://doi.org/10.1177/014920639502100509.

Hurley, R. F., \& Hult, G. T. M. (1998). Innovation, Market Orientation, and Organizational Learning: An Integration and Empirical Examination. Journal of Marketing, 62(3), 42. https://doi.org/10.2307/1251742.

Idaszak, J. R., Bottom, W. P., \& Drasgow, F. (1988). A test of the measurement equivalence of the revised Job Diagnostic Survey: Past problems and current solutions. Journal of Applied Psychology, 73(4), 647-656. https://doi.org/10.1037/0021-9010.73.4.647.

Jackson, P. R., Wall, T. D., Martin, R., \& Davids, K. (1993). New measures of job control, cognitive demand, and production responsibility. Journal of Applied Psychology, 78(5), 753-762. https://doi.org/10.1037/0021-9010.78.5.753.

Kanter, R. M. (1983). The change masters: Innovations for productivity in the American corporation / Rosabeth Moss Kanter. New York: Simon and Schuster.

Kearns, G. S., \& Lederer, A. L. (2003). A Resource-Based View of Strategic IT Alignment: How Knowledge Sharing Creates Competitive Advantage. Decision Sciences, 34(1), 1-29. https://doi.org/10.1111/1540-5915.02289.

Kenny, D. A. (1975). Cross-lagged panel correlation: A test for spuriousness. Psychological Bulletin, 82(6), 887-903. https://doi.org/10.1037/0033-2909.82.6.887.

Kim, W. C., \& Mauborgne, R. (1997). Value innovation: The strategic logic of high growth. Harvard Business Review, 75(1), 102-112.

Kimberly, J., \& Evanisko, M. J. (1981). Organizational Innovation: The Influence of Individual, Organizational, and Contextual Factors on Hospital Adoption of Technological and Administrative Innovations. Academy of Management Journal, 24(4), 689-713. https://doi.org/10.2307/256170. 
Kimberly, John., \& Nielsen, W. (1975). Organization Development and Change in Organizational Performance. Administrative Science Quarterly, 20(2), 191. https://doi.org/10.2307/2391694.

Knolmayer, G. F., \& Röthlin, M. (2006). Quality of Material Master Data and Its Effect on the Usefulness of Distributed ERP Systems. In J. F. Roddick (Ed.), Lecture notes in computer science, 0302-9743: Vol. 4231. Advances in conceptual modeling - theory and practice: ER 2006 workshops BP-UML, CoMoGIS, COSS, ECDM, OIS, QoIS, SemWAT, Tucson, AZ, USA, November 6-9, 2006 ; proceedings / John F. Roddick ... [et al.] (eds.) (Vol. 4231, pp. 362371). Berlin, London: Springer. https://doi.org/10.1007/11908883_43.

Kock, N. (2015). Common Method Bias in PLS-SEM. International Journal of E-Collaboration, 11(4), 110. https://doi.org/10.4018/ijec.2015100101.

Kock, N., \& Hadaya, P. (2018). Minimum sample size estimation in PLS-SEM: The inverse square root and gamma-exponential methods. Information Systems Journal, 28(1), 227-261. https://doi.org/10.1111/isj.12131.

Komssi, M., Kauppinen, M., Töhönen, H., Lehtola, L., \& Davis, A. (2015). Roadmapping problems in practice: Value creation from the perspective of the customers. Requirements Engineering, 20(1), 45-69. https://doi.org/10.1007/s00766-013-0186-3.

Kooper, M. N., Maes, R., \& Lindgreen, E.E.O. R. (2011). On the governance of information: Introducing a new concept of governance to support the management of information. International Journal of Information Management, 31(3), 195-200. https://doi.org/10.1016/j.ijinfomgt.2010.05.009.

Korhonen, J. J., Melleri, I., Hiekkanen, K., \& Helenius, M. (2013). Designing Data Governance Structure An Organizational Perspective. GSTF Journal on Computing (JoC), 2(4).

Krinsky, R., \& Jenkins, A. C. (1997). Collide: When the uneasy fusion of strategy and innovation. Strategy \& Leadership, 25(4), 37-41. https://doi.org/10.1108/eb054594.

Kumar, V., Aksoy, L., Donkers, B., Venkatesan, R., Wiesel, T., \& Tillmanns, S. (2010). Undervalued or Overvalued Customers: Capturing Total Customer Engagement Value. Journal of Service Research, 13(3), 297-310. https://doi.org/10.1177/1094670510375602.

Leenheer, P. de, Christiaens, S., \& Meersman, R. (2010). Business semantics management: A case study for competency-centric HRM. Computers in Industry, 61(8), 760-775. https://doi.org/10.1016/j.compind.2010.05.005.

Lorenzi, N. M., \& Riley, R. T. (2003). Organizational issues = change. International Journal of Medical Informatics, 69(2-3), 197-203.

Lowry, P. B., \& Gaskin, J. (2014). Partial Least Squares (PLS) Structural Equation Modeling (SEM) for Building and Testing Behavioral Causal Theory: When to Choose It and How to Use It. IEEE Transactions on Professional Communication, 57(2), 123-146. https://doi.org/10.1109/TPC.2014.2312452.

Magpili, N. C., \& Pazos, P. (2018). Self-Managing Team Performance: A Systematic Review of Multilevel Input Factors. Small Group Research, 49(1), 3-33. https://doi.org/10.1177/1046496417710500. 
Maltz, E., \& Kohli, A. K. (2000). Reducing Marketing's Conflict with Other Functions: The Differential Effects of Integrating Mechanisms. Journal of the Academy of Marketing Science, 28(4), 479492. https://doi.org/10.1177/0092070300284002.

Mantelero, A. (2014). The future of consumer data protection in the E.U. Re-thinking the "notice and consent" paradigm in the new era of predictive analytics. Computer Law \& Security Review, 30(6), 643-660. https://doi.org/10.1016/j.clsr.2014.09.004.

McNulty, J. E. (1962). Organizational Change in Growing Enterprises. Administrative Science Quarterly, 7(1), 1. https://doi.org/10.2307/2390631.

Meyers, L. S., Gamst, G., \& Guarino, A. J. (2013). Applied multivariate research: Design and interpretation / Lawrence S. Meyers, Glenn Gamst and A.J. Guarino (2nd ed.). Thousand Oaks, Calif., London: Sage.

Mhatre, K. H. (2014). Transformational and charismatic leadership: The road ahead. Oxford University Press. https://doi.org/10.1093/oxfordhb/9780199755615.013.012.

Miles, R. E., \& Snow, C. C. (1992). Causes of Failure in Network Organizations. California Management Review, 34(4), 53-72. https://doi.org/10.2307/41166703.

Miller, N., \& Brewer, M. B. (1984). Groups in contact: The psychology of desegregation / edited by Norman Miller, Marilynn B. Brewer. Orlando, London: Academic.

Mittal, S., \& Dhar, R. L. (2015). Transformational leadership and employee creativity. Management Decision, 53(5), 894-910. https://doi.org/10.1108/MD-07-2014-0464.

Moormann, J., \& Palvolgyi, E. Z. (2013). Customer-Centric Business Modeling: Setting a Research Agenda. In 2013 IEEE 15th Conference on Business Informatics (pp. 173-179). IEEE. https://doi.org/10.1109/CBI.2013.33.

Naletelich, K. (2015). Creativity and Innovation: Defining and Distinguishing the Constructs Within Marketing Strategy.

Niemi, E., \& Laine, S. (2016). Designing Information Governance with a Focus on Competence Management in a Knowledge-Intensive Project Organization: Conference: ICIQ.

Otto, B. (2011). Data Governance. Business \& Information Systems Engineering, 3(4), 241-244. https://doi.org/10.1007/s12599-011-0162-8.

Payne, A., \& Frow, P. (2005). A Strategic Framework for Customer Relationship Management. Journal of Marketing, 69(4), 167-176. https://doi.org/10.1509/jmkg.2005.69.4.167.

Peng, D. X., \& Lai, F. (2012). Using partial least squares in operations management research: A practical guideline and summary of past research. Journal of Operations Management, 30(6), 467-480. https://doi.org/10.1016/j.jom.2012.06.002.

Pierce, J. L., \& Delbecq, A. L. (1977). Organization Structure, Individual Attitudes and Innovation. The Academy of Management Review, 2(1), 27. https://doi.org/10.2307/257602.

Pinsonneault, A., \& Kraemer, K. (1993). Survey Research Methodology in Management Information Systems: An Assessment. Journal of Management Information Systems, 10(2), 75-105. https://doi.org/10.1080/07421222.1993.11518001. 
Pinto, M., Pinto, J., \& Prescott, J. E. (1993). Antecedents and Consequences of Project Team CrossFunctional Cooperation. Management Science, 39(10), 1281-1297. https://doi.org/10.1287/mnsc.39.10.1281.

Plotkin, D. (2013). Data stewardship: An actionable guide to effective data management and data governance. Safari Tech Books Online. Amsterdam: Morgan Kaufmann/Elsevier. Retrieved from http://proquest.safaribooksonline.com/9780124103894.

Podsakoff, P., MacKenzie, S. B., Lee, J.-Y., \& Podsakoff, N. (2003). Common method biases in behavioral research: a critical review of the literature and recommended remedies. The Journal of Applied Psychology, 88(5), 879-903. https://doi.org/10.1037/0021-9010.88.5.879.

Poon, W.-Y., Leung, K., \& Lee, S.-Y. (2002). The Comparison of Single Item Constructs by Relative Mean and Relative Variance. Organizational Research Methods, 5(3), 275-298. https://doi.org/10.1177/1094428102005003005.

Porter, M. (1998). Competitive advantage: Creating and sustaining superior performance : with a new introduction / Michael E. Porter. New York, London: Free Press.

Porter, T., \& Lilly, B. S. (1996). The Effects of Conflict, Trust, And Task Commitment on Project Team Performance. International Journal of Conflict Management, 7(4), 361-376. https://doi.org/10.1108/eb022787.

Ramani, G., \& Kumar, V. (2008). Interaction Orientation and Firm Performance. Journal of Marketing, 72(1), 27-45. https://doi.org/10.1509/jmkg.72.1.27.

Ritter, T., Wilkinson, I. F., \& Johnston, W. J. (2002). Measuring network competence: Some international evidence. Journal of Business \& Industrial Marketing, 17(2/3), 119-138. https://doi.org/10.1108/08858620210419763.

Roznowski, M. (1989). Examination of the measurement properties of the Job Descriptive Index with experimental items. Journal of Applied Psychology, 74(5), 805-814. https://doi.org/10.1037/0021-9010.74.5.805.

Sackett, P. R., \& Larson, J. (1990). Research strategies and tactics in I/O psychology. Consulting Psychologists Press.

Sarin, S., \& McDermott, C. (2003). The Effect of Team Leader Characteristics on Learning, Knowledge Application, and Performance of Cross-Functional New Product Development Teams. Decision Sciences, 34(4), 707-739. https://doi.org/10.1111/j.1540-5414.2003.02350.x.

Sawhney, M., Verona, G., \& Prandelli, E. (2005). Collaborating to create: The Internet as a platform for customer engagement in product innovation. Journal of Interactive Marketing, 19(4), 4-17. https://doi.org/10.1002/dir.20046.

Schriesheim, C. A., \& Eisenbach, R. J. (1995). An Exploratory and Confirmatory Factor-Analytic Investigation of Item Wording Effects on the Obtained Factor Structures of Survey Questionnaire Measures. Journal of Management, 21(6), 1177-1193. https://doi.org/10.1177/014920639502100609.

Seiner, R. S. (2014). Non-invasive data governance: The path of least resistance and greatest success (1st ed.). Basking Ridge, N.J.: Technics Pub. 
Sethi, R. (2000). Superordinate Identity in Cross-Functional Product Development Teams: Its Antecedents and Effect on New Product Performance. Journal of the Academy of Marketing Science, 28(3), 330-344. https://doi.org/10.1177/0092070300283003.

Sherif, M. (1988). The Robbers Cave experiment: Intergroup conflict and cooperation / Muzafer Sherif ... [et al.] ; with a new introduction by Donald T. Campbell (1st Wesleyan ed.). Middletown, Conn.: Wesleyan University Press; Scranton.

Silvola, R., Jaaskelainen, O., Kropsu-Vehkapera, H., \& Haapasalo, H. (2011). Managing one master data - challenges and preconditions. Industrial Management \& Data Systems, 111(1), 146162. https://doi.org/10.1108/02635571111099776.

Simsarian Webber, S. (2002). Leadership and trust facilitating cross-functional team success. Journal of Management Development, 21(3), 201-214. https://doi.org/10.1108/02621710210420273.

Sofer, C. (1964). The Assessment of Organizational Change. Journal of Management Studies, 1(2), 128-142. https://doi.org/10.1111/j.1467-6486.1964.tb00128.x.

Swanson, E. B. (1974). Management Information Systems: Appreciation and Involvement. Management Science, 21(2), 178-188. https://doi.org/10.1287/mnsc.21.2.178.

Thamhain, H. J. (2007). Team Building in Project Management. In D. I. Cleland \& W. R. King (Eds.), Project Management Handbook (2nd ed., pp. 823-846). Hoboken: Wiley [Imprint]; John Wiley \& Sons, Incorporated. https://doi.org/10.1002/9780470172353.ch32.

Vanlommel, E., \& Brabander, B. de. (1975). The Organization of Electronic Data Processing (EDP) Activities and Computer Use. The Journal of Business, 48(3), 391-410. Retrieved from https://ideas.repec.org/a/ucp/jnlbus/v48y1975i3p391-410.html.

Vayghan, J. A., Garfinkle, S. M., Walenta, C., Healy, D. C., \& Valentin, Z. (2007). The internal information transformation of IBM. IBM Systems Journal, 46(4), 669-683. https://doi.org/10.1147/sj.464.0669.

Villar, M. (2009). Establishing Effective Business Data Stewards. Business Intelligence Journal, 14(2).

Vilminko-Heikkinen, R., \& Pekkola, S. (2017). Master data management and its organizational implementation. Journal of Enterprise Information Management, 30(3), 454-475. https://doi.org/10.1108/JEIM-07-2015-0070.

Vrhovec, S. L.R., Hovelja, T., Vavpotič, D., \& Krisper, M. (2015). Diagnosing organizational risks in software projects: Stakeholder resistance. International Journal of Project Management, 33(6), 1262-1273. https://doi.org/10.1016/j.ijproman.2015.03.007.

Wang, C., \& Chung, H. F.L. (2013). The moderating role of managerial ties in market orientation and innovation: An Asian perspective. Journal of Business Research, 66(12), 2431-2437. https://doi.org/10.1016/j.jbusres.2013.05.031.

Weber, K., Otto, B., \& Österle, H. (2009). One Size Does Not Fit All---A Contingency Approach to Data Governance. Journal of Data and Information Quality, 1(1), 1-27. https://doi.org/10.1145/1515693.1515696.

Webster, J., \& Watson, R. T. (2002). Analyzing the past to prepare for the future: Writing a literature review. MIS Quarterly, 26(2), xiii-xxiii. 
Wende, K. (2007). A Model for Data Governance - Organising Accountabilities for Data Quality Management. 18th Australasian Conference on Information Systems.

Wofford, J. C., \& Liska, L. Z. (1993). Path-Goal Theories of Leadership: A Meta-Analysis. Journal of Management, 19(4), 857-876. https://doi.org/10.1177/014920639301900407.

Zaltman, G., Duncan, R., \& Holbek, J. (1973). Innovations and organizations. New York, London: Wiley-Interscience.

The research paper has been reviewed. | Received: February 1, 2019; Accepted: May 29, 2019;

Prepublished online: June 10, 2019; Published: June 19, 2019 


\section{Appendix}

\section{Table 1 | Survey Questions}

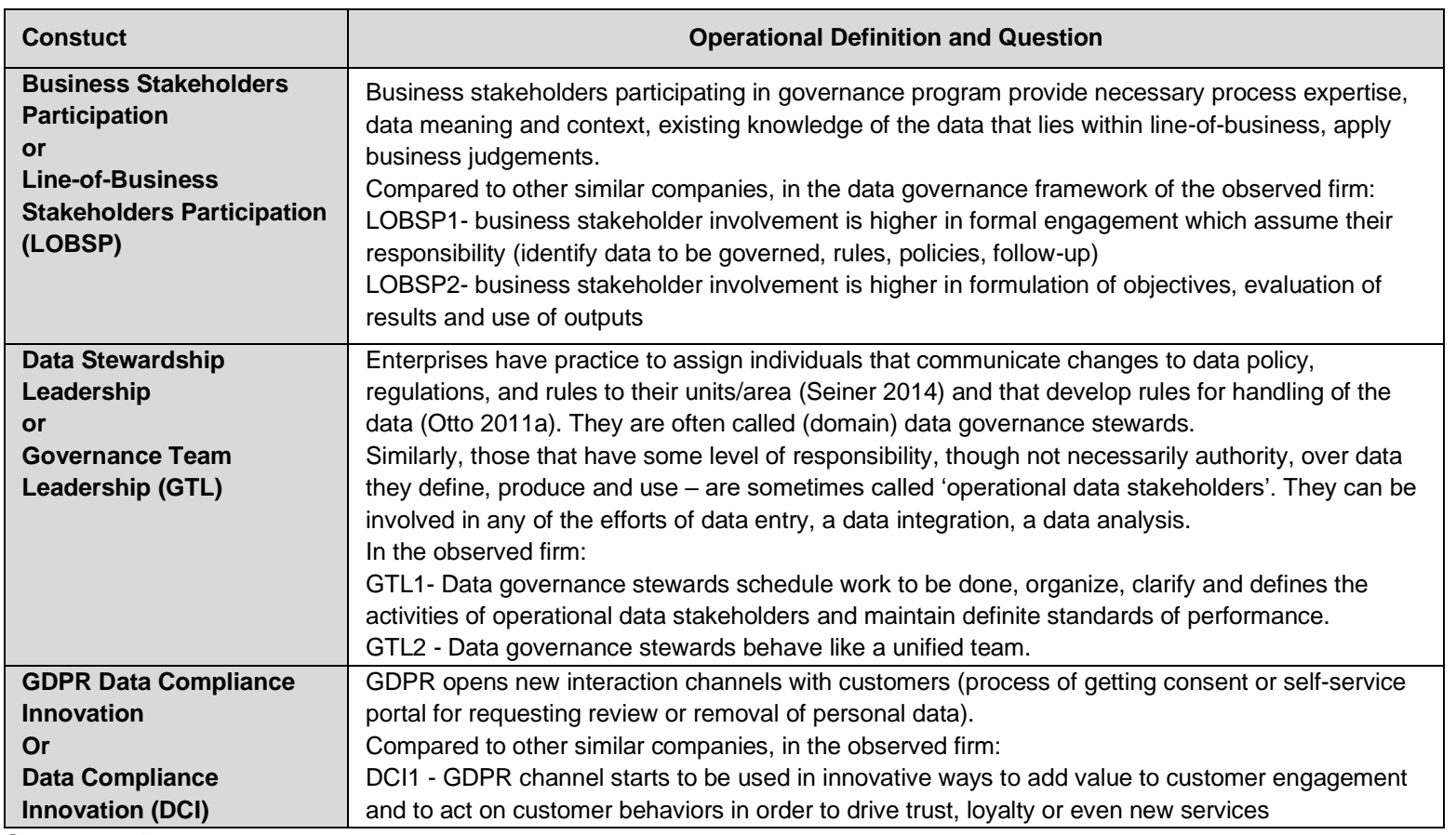

Source: authors 
Table 2 | Descriptive Statistics

\begin{tabular}{|l|c|c|c|c|c|c|c|c|c|}
\hline & No. & Missing & Mean & Median & Min & Max & $\begin{array}{c}\text { Standard } \\
\text { Deviation }\end{array}$ & $\begin{array}{c}\text { Excess } \\
\text { Kurtosis }\end{array}$ & Skewness \\
\hline LOBSP1 & 1 & 0 & 3.816 & 4 & 1 & 5 & 0.983 & 0.317 & -0.864 \\
\hline LOBSP2 & 2 & 0 & 3.663 & 4 & 1 & 5 & 0.999 & -0.497 & -0.585 \\
\hline GTL1 & 5 & 0 & 3.439 & 4 & 1 & 5 & 1.079 & -0.465 & -0.557 \\
\hline GTL2 & 6 & 0 & 3.133 & 3 & 1 & 5 & 1.046 & -0.821 & 0.001 \\
\hline DCl1 & 11 & 0 & 3 & 3 & 1 & 5 & 1.107 & -0.945 & -0.046 \\
\hline
\end{tabular}

Source: authors

Table 3 | Constuct Reliability and Validity

\begin{tabular}{|l|c|c|c|}
\hline & Cronbach's Alpha & Composite Reliability & $\begin{array}{c}\text { Average Variance } \\
\text { Extracted (AVE) }\end{array}$ \\
\hline LOBSP & 0.827 & 0.921 & 0.857 \\
\hline DCI & 1 & 1 & 1 \\
\hline GTL & 0.777 & 0.9 & 0.818 \\
\hline
\end{tabular}

Source: authors

Table 4 | Factor Loadings (Outer Loadings), Principal Component Analysis and Item-Total-Loadings

\begin{tabular}{|l|c|c|c|c|c|}
\hline & LOBSP & DCI & GTL & $\begin{array}{c}\text { Principal } \\
\text { Component } \\
\text { Analysis }\end{array}$ & $\begin{array}{c}\text { Item-Total- } \\
\text { Loadings }\end{array}$ \\
\hline LOBSP1 & 0.923 & & & 0.75 & 0.72 \\
\hline LOBSP2 & 0.925 & & & 0.71 & 0.68 \\
\hline GTL1 & & & 0.887 & 0.61 & 0.66 \\
\hline GTL2 & & & 0.92 & 0.68 & 0.60 \\
\hline DCl1 & & 1 & & 0.47 & 0.61 \\
\hline
\end{tabular}

Source: authors 
Table 5 | Confirmatory Factor Analysis

\begin{tabular}{|l|c|c|c|}
\hline & LOBSP & DCI & GTL \\
\hline LOBSP1 & $\mathbf{0 . 9 2}$ & 0.32 & 0.44 \\
\hline LOBSP2 & $\mathbf{0 . 9 2}$ & 0.23 & 0.49 \\
\hline GTL1 & 0.43 & 0.03 & $\mathbf{0 . 8 9}$ \\
\hline GTL2 & 0.48 & 0.17 & $\mathbf{0 . 9 2}$ \\
\hline DCl1 & 0.3 & $\mathbf{1}$ & 0.12 \\
\hline
\end{tabular}

Source: authors

Table 6 | Fortner-Larcker Matrix

\begin{tabular}{|l|c|c|c|}
\hline & LOBSP & DCI & GTL \\
\hline LOBSP & 0.923 & & \\
\hline DCI & 0.297 & 1 & \\
\hline GTL & 0.504 & 0.117 & 0.904 \\
\hline
\end{tabular}

Source: authors

\section{Table 7 | Model Fit}

\begin{tabular}{|l|c|c|c|}
\hline & SSO & SSE & Q $^{2}$ (=1-SSE/SSO) \\
\hline LOBSP & 196 & 156.113 & 0.204 \\
\hline DCI & 98 & 95.307 & 0.027 \\
\hline GTL & 196 & 196 & \\
\hline
\end{tabular}

Source: authors 


\section{Table 8 | F Square}

\begin{tabular}{|l|c|c|c|}
\hline & DG Span & DCI & GTL \\
\hline LOBSP & 0.084 & & \\
\hline DCI & & & \\
\hline GTL & 0.341 & 0.002 & \\
\hline
\end{tabular}

Source: authors

\section{Table 9 | Demographics (all industries)}

\begin{tabular}{|l|c|c|c|c|c|c|}
\hline & Count of EF1 & $\begin{array}{c}\text { Average of } \\
\text { GTL1 }\end{array}$ & $\begin{array}{c}\text { Average of } \\
\text { GTL2 }\end{array}$ & $\begin{array}{c}\text { Average of } \\
\text { LOBSP1 }\end{array}$ & $\begin{array}{c}\text { Average of } \\
\text { LOBSP2 }\end{array}$ & $\begin{array}{c}\text { Average of } \\
\text { DCl1 }\end{array}$ \\
\hline CEE & 20 & 3.25 & 3.15 & 3.75 & 3.70 & 2.85 \\
\hline OEU & 8 & 3.88 & 3.38 & 4.25 & 4.25 & 3.00 \\
\hline SE & 21 & 3.57 & 2.90 & 3.95 & 3.67 & 3.05 \\
\hline WE & 49 & 3.39 & 3.18 & 3.71 & 3.55 & 3.04 \\
\hline Grand Total & 98 & 3.44 & 3.13 & 3.82 & 3.66 & 3.00 \\
\hline
\end{tabular}

Source: authors

\section{Table 10 | Path Coefficients and P Values}

\begin{tabular}{|l|l|l|}
\hline & Path Coefficient & P Value \\
\hline LOBSP - DCI & -0.044 & 0.016 \\
\hline GTL - LOBSP & 0.504 & 0.001 \\
\hline GTL - DCI & 0.319 & 0.746 \\
\hline
\end{tabular}

Source: authors 